\title{
The processing accuracy of the gear
}

\author{
Sergiu Mazuru*, Maxim Casian, and Serghei Scaticailov \\ Technical University of Moldova, 9, Studenţilor str. Chişinău, Republic of Moldova
}

\begin{abstract}
The paper presents analysis of processing quality of gears. A special attention was drawn to detecting and removing burns, the existence of which greatly reduced operating properties of gears. The study emphases the influence of schemes, processing modes and abrasive tools features on the physico-mechanical layer of teeth processed and phase changes, micro-cracks appearances, depth and degree of hardening, meaning and character of residual stresses distribution.
\end{abstract}

\section{Introduction}

The formation of the surface layer during deep grinding of gears from alloyed steels occur under the influence of an uneven thermodynamic influence on the work-piece and, as a consequence, the appearance of inhomogeneous elasto-plastic deformations along the section of cavity profile between the adjacent teeth and the structure-phase transformations from heating and cooling of metal. This leads to distortion of the teeth profile, to the appearance of a step error and a decrease in the kinematic accuracy of the gear and to the appearance of grinding defects on the treated surfaces. Experience shows that the accuracy of machining of gears depends not only on the rigidity and kinematic accuracy of the machine, but also on the accepted grinding modes, tool characteristics and the conditions of its correctness.

The following describes an example of the profile deep grinding of identical gears on the same P600G machine with a grinding wheel with one characteristic. With the option of processing in a softer profiling mode, when the total allowance was divided into 5 passes, the accuracy of the gear wheel was achieved no less than with the optimal version in 2 passes.

As an example illustrating the accuracy of this processing process, measurements are given of spur gears manufactured by ARP GmbH Alpirsbah (Germania) with the following specifications: module $-5 \mathrm{~mm}$, angle of engagement $-20^{\circ}$, number of teeth -23 , width of sprocket $-80 \mathrm{~mm}$. Accuracy of gears according to DIN 3062 - 6th qualitet.

The gears were machined by the method of profile deep grinding on a 53A30P machine model with a highly porous disk with the characteristic $25 \mathrm{~A} 16 \mathrm{PM} 212 \mathrm{~K}$. The preliminary profiling of the teeth was carried out by the method of deep grinding in 2 passes, and after carburizing with quenching, fine grinding was also performed in 2 passes. The meshing parameters were measured on a special-purpose gear-measuring center model P $100 \mathrm{CNC}$ from company Klingelnberg. Measurement protocols containing graphical and digital information on the accuracy of profiles and tooth lines, as well the step errors and radial runout of the sprocket are shown in Figure 1 in accordance with GOST 1643-81.

*Corresponding author: s_mazuru@mail.utm.md 
The received high accuracy of gear wheel processing is provided due to the kinematics of profile grinding process (absence of the long and difficult kinematic chains, control from highly developed system of (NC) and high dimensional stability of the abrasive tool. The requirements of the drawing and the results of measuring the processing accuracy parameters after grinding with a high porosity circle are given in Table 1.

Table 1. Precision parameters of gears

\begin{tabular}{|c|c|c|c|}
\hline Precision parameters & Notation & Tolerance by the drawing, $\boldsymbol{\mu m}$ & The real precision, $\boldsymbol{\mu m}$ \\
\hline Total profile error & $\mathrm{F}_{\mathrm{a}}$ & 12 & $6.4 \div 7.9$ \\
\hline Profile shape deviation & $\mathrm{F}_{\mathrm{fa}}$ & 10 & $6.4 \div 6.8$ \\
\hline The deviation of gear angle & $\mathrm{F}_{\mathrm{ka}}$ & \pm 7 & $-1.5 \div 2.6$ \\
\hline Form error of the tooth straightness & $\mathrm{F}_{\mathrm{P}}$ & 9 & $0.4 \div 0.6$ \\
\hline Angle deviation of the tooth straightness & $\mathrm{F}_{\mathrm{fp}}$ & 10 & $1.2 \div 5.8$ \\
\hline
\end{tabular}

Thermal action during grinding is often accompanied by structural changes in the surface layer of the treated material in the form of burns. Depending on the capacity of the heat source, the time of its action, and also the heat resistance of the processed steel, structural changes can develop into different depths and have a different nature. After the most intense thermal action, the surface layer represents secondary hardening austenitemartensite, under which is located a zone of the secondarily tempered metal with the structure of troostomartensite and troostite. With a decrease of heating of the surface layer, a secondary release structure is formed in it, proceeding through all the stages of tempering into the basic structure of martensite.

The likelihood of the burns appearance during tooth grinding depends not only on the processing conditions of processing, but also on the grade of the steel being processed. For heat-resistant steels of the type AISI 415, 16Cr3NiWMo this probability is lower than for non-heat-resistant steels such as $14 \mathrm{NiCr} 14$ and others [1].

During etching, the areas with a modified microstructure after tooth-grinding are usually extended along the tooth or revealed as a dashed grid, depending on the processing method. The greatest number of burns strokes and their maximum intensity, as a rule, is observed on the heads of ground teeth. Closer to the teeth legs, their number and intensity decrease or they are generally absent. Structural changes cause concomitant changes in the hardness and stress of the surface layer of the treated teeth. The micro-hardness in the burn zones is reduced, and residual tensile stresses are formed in the surface layer. Cogwheels with burns have bending endurance 1.4 to 1.6 times less than ground wheels without burnings. Accordingly, the durability of contact fatigue in gears with burns is 3.5 times lower $[1,2,3,4,5,6$ and 7$]$.

The appearance and development of grinding nature defects, before all, of burns and micro-cracks, caused by structural-phase changes in the surface layer, depends on the temperature and the time of its action. In the gear grinding schemes used, the heating intensity and the degree of its localization greatly differ and are related to the kinematic features of contacting grinding wheel with the profiled surface of the teeth. Under optimal conditions of gear grinding by various rolling patterns or profile processing by highly porous abrasive wheels, as experimental studies have shown, production tests and experience of industrial application, burns and micro-cracks on the machined surfaces of the teeth are not observed.

A general recommendation to prevent grinding defects in all gear grinding schemes is the decrease of the heat source intensity and the heating time of the treated zone. The use of new highly porous circles already by itself reduces the heating temperature by 300 to $400^{\circ}$ C compared to grinding wheels with a normal structure. In combination with the optimization of the processing mode due to the speed increase of the relative movement 
relative to tool and to work-piece, as well as the depth of cutting, their application makes it possible to increase the removal rate of the material and to reduce the time of action of the heat source on the machined surface, that is, to create the prerequisites for highperformance and defect-free grinding. The level of intensification of the processing parameters depends on the selected characteristic of the highly porous grinding wheel.

Thus, taking into account a significant reduction in the operational properties of gears by the formation of defective layers with burns, the introduction of new technologies of non-burn gear grinding is an important condition for ensuring high reliability and durability of tooth wheels in exploitation.

\section{Results of metallographic analysis}

Analyzing the obtained data on the influence of various conditions for the profile deep grinding of the gear wheel from hardened steel $14 \mathrm{NiCr} 14$ (HRC 40) on the formation of surface layer properties. The cavity between the neighboring teeth 2 or $4 \mathrm{~mm}$ in width was profiled in 4-6 passes at a constant processing speed of $20 \mathrm{~m} / \mathrm{s}$ with varying parameters of the grinding mode $t$ and $B_{d}$ with grinding wheels with characteristics 25A12PBM214K5, 25A12PM2.16K5 and 25A16PM2.12K5 for various kinematic schemes of interaction between the tool and the work-piece. The total nominal depth of the cavity after multi-pass treatment varied from 5 to $6.1 \mathrm{~mm}$. The quality of the surface layer by the change in microstructure and micro-hardness was estimated after the final passage. In the process of shaping the profile, after each pass on the machined surfaces of the teeth, defects of the grinding character were visually recorded: burns, traces of crushing and also.

Practically in all cases of profile deep grinding of a conical gear wheel made from $16 \mathrm{Cr} 3 \mathrm{NiWMo}$ steel its initial structure of tempering martensite is transformed into a secondary quenching structure in a thin near-surface layer with an increase in micro hardness followed by a transition to a secondary tempering zone. Under unfavorable conditions of deep grinding in the surface layer, a structure of secondary hardening with increased micro hardness along the valleys and to tooth profile in the form of an ellipse with a width at the center of 0.2 to $0.86 \mathrm{~mm}$ and a length of 1.28 to $5 \mathrm{~mm}$ is observed.

The results of the metallographic study of the grooves microstructure after profile grinding testify to the fact that the groove geometry (cross-sectional area), the scheme and processing regimes, as well as the characteristics of the grinding wheel, have a great influence on the formation nature of the surface layer - the depth of the altered layer and the degree of hardening.

With multi-pass groove profiling of the gear wheel, the technological inheritance from previous passages and their number have a big influence on the quality of the treatment. In this regard, not always the final finishing passes of the grinding wheel can ensure the formation of the surface layer with minimal distortion of its structure. As an example, we can compare the results of processing two different options. In the first variant, in 4 passes, despite the high energy density of $16.2 \mathrm{~J} / \mathrm{mm}$, the quality of the treatment is better than in the other version in 6 passes at a lower energy level of $7.68 \mathrm{~J} / \mathrm{mm}$, this conclusion is confirmed by the example described in [5].

As an additional factor in analyzing the treatment options considered, it is necessary to take into account the scheme of fixing the work-piece, and the direction of movement and rotation of the grinding wheel relative to it. Experiments were carried out on a conical spur gear wheel, which was cantilevered in the mandrel, enabling the implementation of horizontal and vertical profiling schemes. Undoubtedly, for these conditions, a horizontal layout is more preferable for deep grinding, in which higher rigidity of the technological cutting system is achieved. 


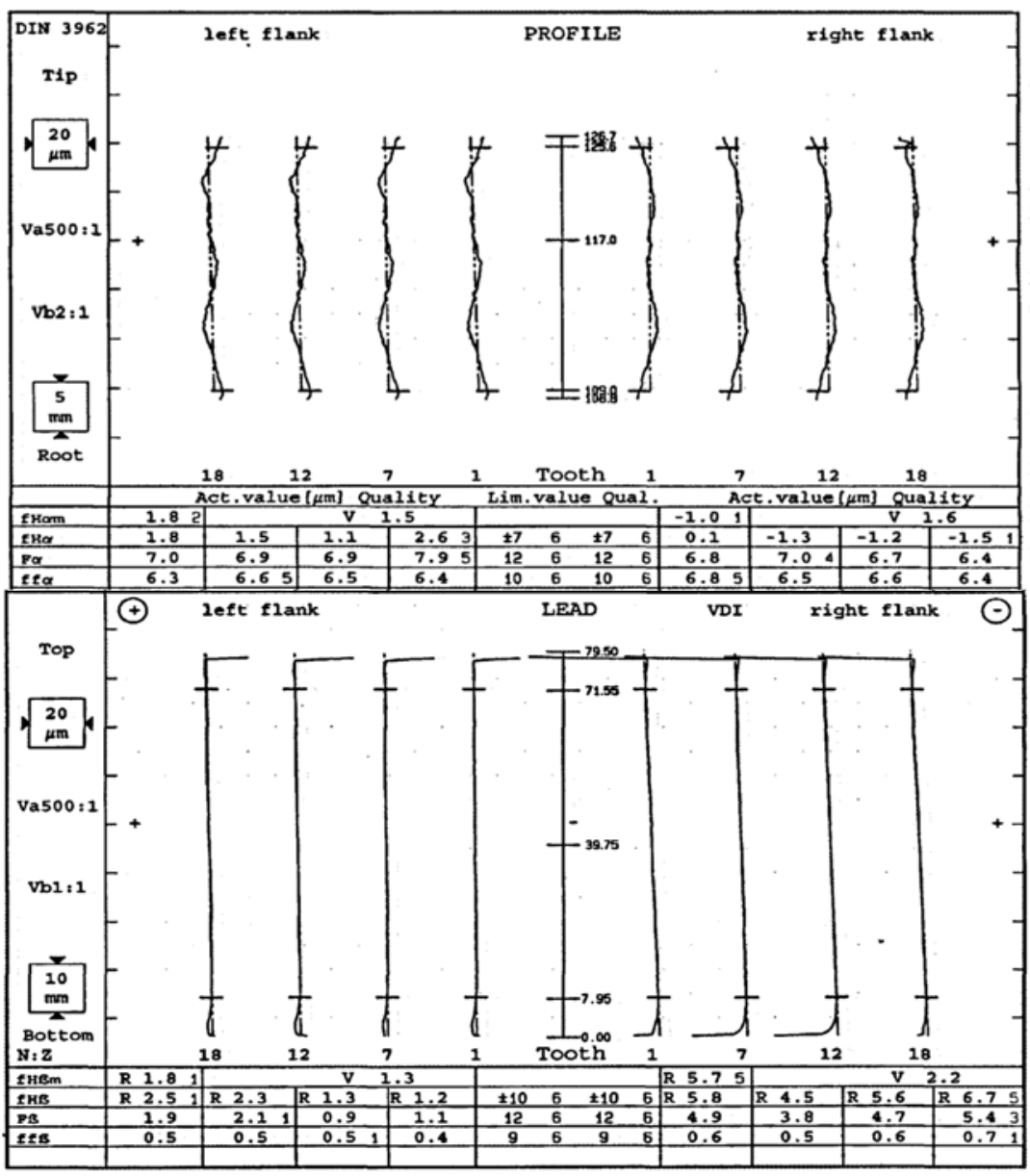

Fig. 1. Results of measuring the accuracy of the profile and the direction of the tooth line.

\section{Elimination of burns}

When assigning the characteristics of a highly porous grinding wheel, it is more expedient to use a tool with a larger grain size and a smaller structure than with a smaller grain and a larger number of the structure. Analyzing the obtained results, it can be concluded that the optimal conditions for the gears profile deep grinding, from the point of view of the surface layer formation with minimal structural changes is the horizontal counter processing scheme with a minimum number of passes with a grinding wheel with the characteristic 25A16PM2.12K5.

In addition to multi-pass groove profiling of the gear wheel, experiments were conducted to evaluate the direct influence of the deep grinding regime on the formation of the surface layer properties. Profiling of the groove with a width of $2 \mathrm{~mm}$ was carried out under optimal grinding conditions with a circle with the characteristic 25A16PM2.12K5 with a horizontal counter processing scheme. The depth of the passage varied from 0.5 to 3 $\mathrm{mm}$, the speed of the longitudinal movement of the tool was chosen in such a way as to ensure the constancy of the item $t x S_{f l}$ equal to $60 \mathrm{~mm} / \mathrm{min}$.

The results of the metallographic study of the surface layer after processing show that the item $t * S A$ is kept constant, the depth of the altered layer $\mathrm{h}$ and the degree of adhesion 
of the treated surface $\mathrm{N}$ increases with increasing depth of the passage $\mathrm{t}$. This is explained by the fact that the depth of cutting during the teeth profiling implicitly affects the actual removal of material inconsistently, the thermodynamic intensity of the process of deep grinding. If the depth $\mathrm{t}$ is increased from 0.5 to $3 \mathrm{~mm}$ or 6 times, the calculated sectional area of the profile groove of the gear rises from $1.09 \mathrm{~mm}$ to $9.28 \mathrm{~mm}$ or 8.5 times, and the actual metal removal speed is $130,9 \mathrm{~mm} / \mathrm{min}$ (at $t=0.5 \mathrm{~mm}, S_{f l}=120 \mathrm{~mm} / \mathrm{min}$ ) to 185.5 $\mathrm{mm} / \mathrm{min}$ (at $t=3 \mathrm{~mm}, B_{d}=20 \mathrm{~mm} / \mathrm{min}$ ) or $42 \%$.

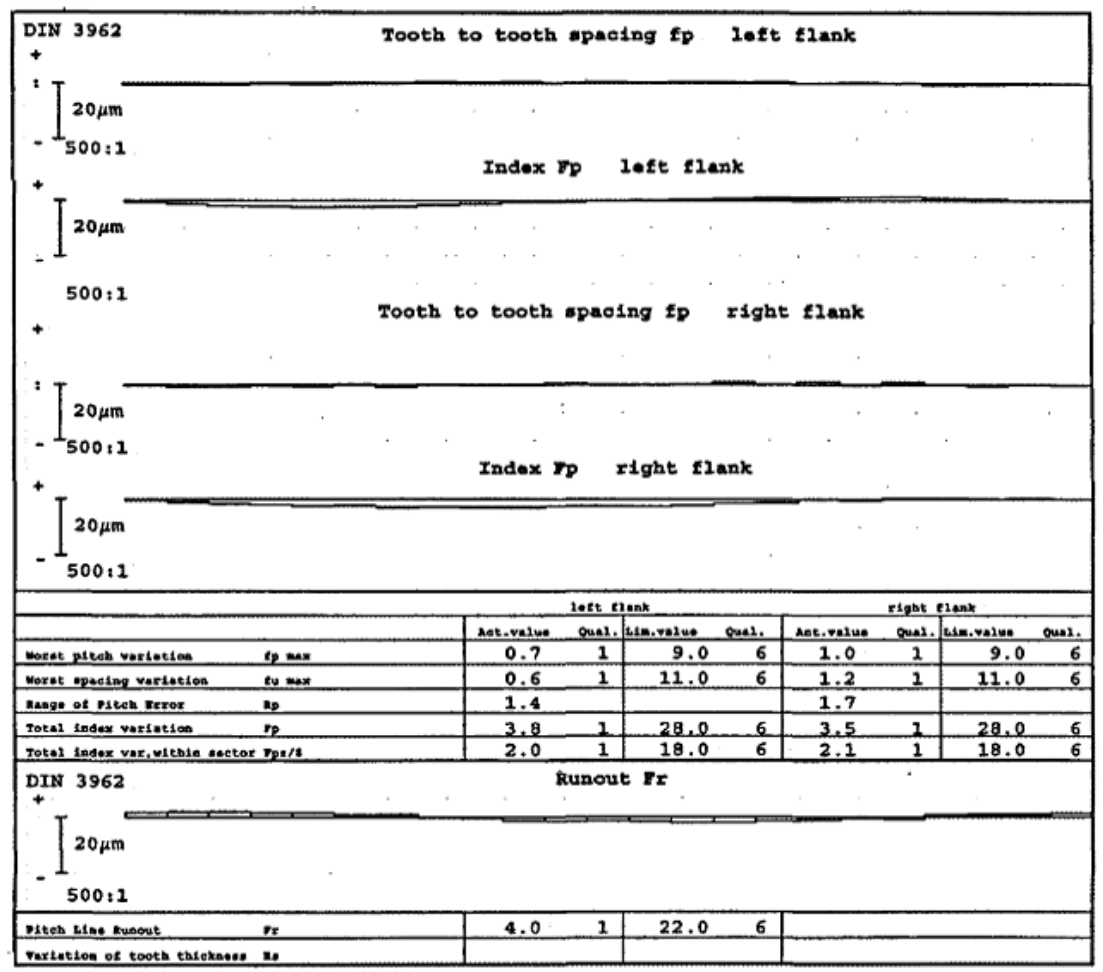

Fig. 2. Results of measuring the stepwise error of the gear.
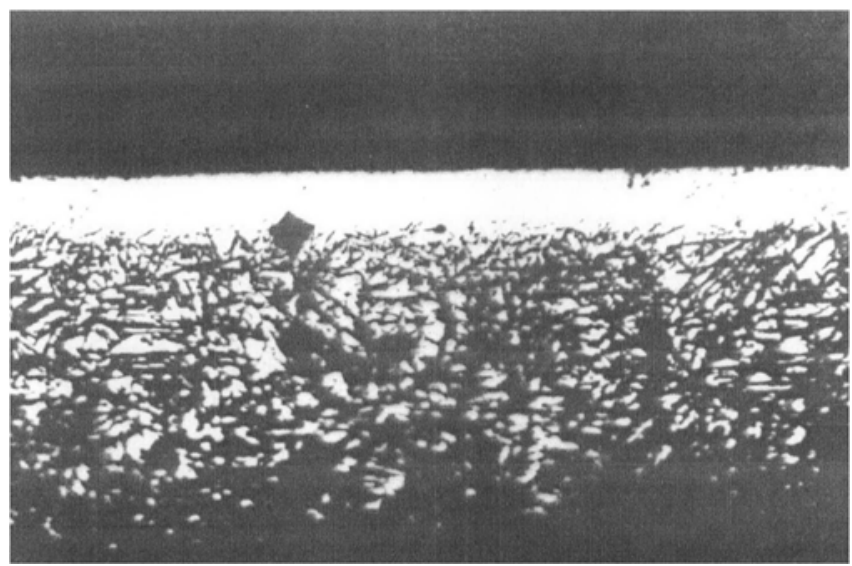

Fig. 3. Gear tooth microstructure, made from steel $14 \mathrm{NiCr} 14$ after grinding with traces of burns (x500). 


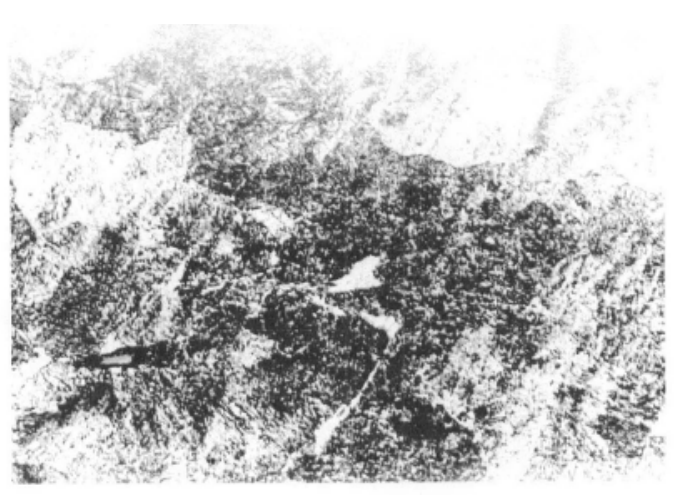

Fig. 4. Initial structure of steel $37 \mathrm{Cr} 4$ (x500).

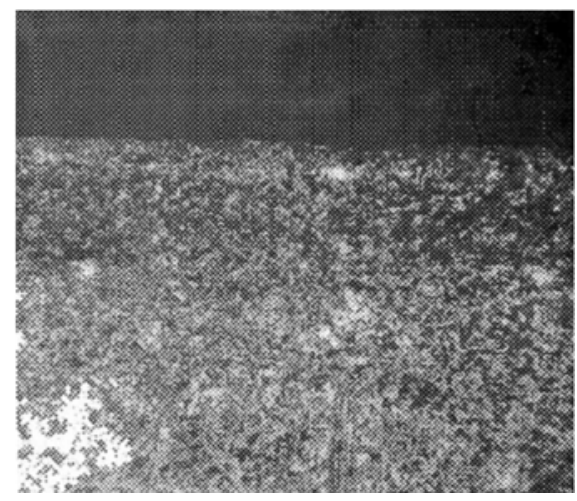

Fig. 5. Outer layer of gear with structural changes.

Figures 4 and 5 show examples of structural changes in the surface layer of the $14 \mathrm{NiCr} 14$ gearwheel grooves before and after the profile grinding. Under optimal conditions for profile deep grinding of the gear wheel, structural changes in the surface layer are not observed (Figure 5).

\section{Conclusions}

Precision of processing gears was rated in accordance with GOST 1643-81 and European standard DIN 3062 after the achieving precision of the profile and tooth line, step error and gear runout. To indicate the optimal constant processing conditions are ensured a level of precision 4-5 depending on the type and condition of the machine used.

Lifetime of the gear wheels, processed by new technology increases about 3 times. This effect is due to the fact that in the surface layer of the work-piece are ensured minimal deviations micro and macro structural at a depth of up to 10 micrometers or excluding them with the forming of compression residual stress of $240 \mathrm{MPa}$ up value.

\section{References}

1. S. Mazuru, A. Vlase, S. Scaticailov, Processing technologies for gear cutting machines (Tehnica-U.T.M. Publishing House, Chişinău, Republic of Moldova, 2014)

2. I. Bostan, V. Dulgheru, C. Gluşco, S. Mazuru, M. Vaculenco, Anthalogy of Inventions. (Chişinău: Bons Offices, 2011)

3. I. Bostan, S. Mazuru, S. Scaticailov, M. Casian, Precession transmission. Patent nr. 1116, BOPI nr. $1 / 2017$

4. I. Bostan, S. Mazuru, S. Scaticailov, Proceedings of TEHNOMUS Conference (Ştefan cel Mare University of Suceava, România, 2013)

5. V. Botnari and S. Mazuru, Applied Mechanics and Materials 657 147-153 (2014)

6. S. Mazuru and M. Casian, Advanced Materials Research 1036 286-291 (2014)

7. M. Casian and S. Mazuru, Advanced Materials Research 1036 292-297 (2014) 